\title{
Hypercontractile Esophagus With Atypical Symptoms
}

\author{
Yoon Jin Choi ${ }^{1}$ and Nayoung Kim ${ }^{1,2 *}$ \\ ${ }^{1}$ Department of Internal Medicine, Seoul National University Bundang Hospital, Seoungnam, Gyeonggi-do, Korea; and \\ ${ }^{2}$ Department of Internal Medicine and Liver Research Institute, Seoul National University College of Medicine, Seoul, Korea
}

A 57-year-old man presented with frequent belching for 10 years. Some ambiguous chest discomforts had usually preceded and often disappeared after belching. However, when the discomfort persisted even after belching, he often felt dizziness. Chest pain and gastroesophageal regurgitation were not accompanied. He underwent coronary angiography and tests for arrhythmia, but no abnormal findings were found. He had visited many gastroenterologic clinics because of the aggravated symptoms and took several medicines including proton pump inhibitors for the last 2 years, but the symptoms did not improve.

After he was referred to our hospital, he underwent gastroduodenal endoscopy. Whitish discoloration of gastroesophageal junction was observed, which was minimal changes of reflux esophagitis. Under the suspicion of the combined esophageal dysmotility, high-resolution impedance manometry (HRIM) was recommended with $\mathrm{pH}$ monitoring. HRIM in upright position revealed vigorous esophageal contraction which exceeded $8,000 \mathrm{mmHg} \cdot \mathrm{sec} \cdot \mathrm{cm}$ of distal contractile integral (DCI) in most of the 10 times liquid-swallowing (Figure). Although integrated relaxation pressure was slightly elevated, peristalsis was intact. Also, contractile front velocity and distal latency were within normal range. Collectively, these results were compatible with Jack- hammer esophagus. However, he refused the ambulatory 24-hour esophageal $\mathrm{pH}$ monitoring.

The patient was prescribed $60 \mathrm{mg}$ of nifedipine daily for 8 weeks and instructed to take $5 \mathrm{mg}$ of flunarizine if he felt dizziness. He eventually reported decreased frequency and se-

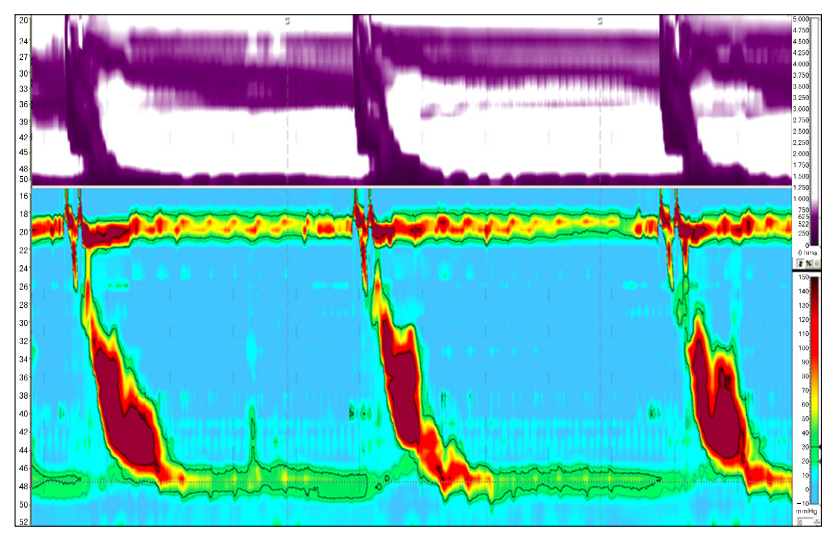

Figure. High-resolution impedance manometry of a patient with hypercontractile esophagus. Extremely abnormal contraction (DCI > $8,000 \mathrm{mmHg} \cdot \mathrm{sec} \cdot \mathrm{cm})$ is noted. The esophago-gastric junction relaxation is equivocal (integrated relaxation pressure $[\mathrm{IRP}]=16$ $\mathrm{mmHg}$ ) but the distal latency ( $\mathrm{DL}>4.5$ seconds) is normal.

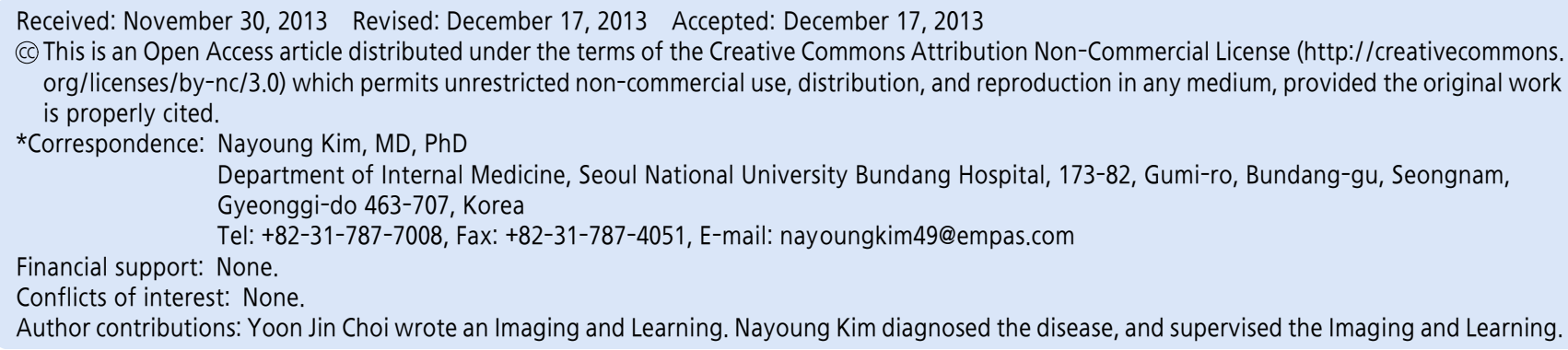


verity of belching and dizziness up to $80 \%$ compared to baseline.

The current Chicago classification of esophageal motility disorders defines a hypercontractile esophagus by the presence of at least one contraction over $8,000 \mathrm{mmHg} \cdot \mathrm{sec} \cdot \mathrm{cm}-\mathrm{DCI}$. ${ }^{1}$ This motility disorder is rare as to be $4.1 \%$ among 200 patient's series $^{2}$ and displays dysphagia, reflux or chest pain. ${ }^{3}$ Current pathophysiologic concept for hypercontractile esophagus includes excessive cholinergic drive or hypertrophy of myocytes. ${ }^{4}$ Therefore, in the absence of abnormality of lower esophageal sphincter relaxation, nitrate and calcium channel blockers can be recommended for this motility disorder.

Belching is not a typical symptom of esophageal hypertensive peristaltic disorder. It is also possible that gastroesophageal reflux disease which might coexist with Jackhammer esophagus could cause belching. ${ }^{5}$ However, regarding that the improvement of symptoms with calcium-channel blockers, which had been refractory to the previous proton pump inhibitor therapy, we cannot exclude a certain relationship between this esophageal dysmotility and belching in this case.

\section{References}

1. Bredenoord AJ, Fox M, Kahrilas PJ, et al. Chicago classification criteria of esophageal motility disorders defined in high resolution esophageal pressure topography1. Neurogastroenterol Motil 2012;24(suppl 1):57-65.

2. Roman S, Pandolfino JE, Chen J, Boris L, Luger D, Kahrilas PJ. Phenotypes and clinical context of hypercontractility in high-resolution esophageal pressure topography (EPT). Am J Gastroenterol 2011;107:37-45.

3. Roman S, Tutuian R. Esophageal hypertensive peristaltic disorders. Neurogastroenterol Motil 2012;24(suppl 1):32-39.

4. Dogan I, Puckett JL, Padda BS, Mittal RK. Prevalence of increased esophageal muscle thickness in patients with esophageal symptoms. Am J Gastroenterol 2007;102:137-145.

5. Hemmink GJ, Bredenoord AJ, Weusten BL, Timmer R, Smout AJ. Supragastric belching in patients with reflux symptoms. Am J Gastroenterol 2009;104:1992-1997. 